\section{Simply Good Eating for English Language Learners Program Demonstrates Positive Participant Outcomes}

Shelley Sherman, Kathleen D. Lovett, Christine A. Barno, Abby Gold, G. Ali Hurtado, Ju Ri Joeng

\section{d}

UNIVERSITY OF MINNESOTA EXTENSION

\section{ABSTRACT}

The Simply Good Eating for English Language Learners curriculum has been in use in Minnesota since 2008. It uses a hands-on

approach to teach nutrition concepts to immigrants and others with limited English skills.

Recent analysis of survey data indicated statistically significant improvements in reported food intake, food safety and food resource management practices related to the number of sessions attended.

\section{OBJECTIVE}

To evaluate the effectiveness of a nutrition education program designed to address the unique learner needs of ELL (English Language Learner) participants

\section{TARGET AUDIENCE}

Multi-ethnic, multi-lingual, low income adults (72\% female) in urban and rural settings, seen through the SNAP-Ed program.

\section{METHODS}

Description: Lesson objectives focused on increasing physical activity and fruit and vegetable intake, decreasing sugar and fat intake, stretching the food dollar, and handling food safely. Each participant received an average of 6.5 hours of instruction over a 3 month period, through a series of interactive, hands-on lessons using visuals and actual food products.

Evaluation: Participants completed pre and post surveys ( 9 questions for each) to measure changes in food intake, resource management and food safety practices. Questions contained pictures with text to facilitate participant understanding.

The Wilcoxon Signed Ranks test and paired t-tests were used to examine changes in outcome measures. Correlations analysis between measured outcomes and number of sessions attended was also conducted.

Use of Theory: The program used an evidence-informed curriculum based in social cognitive theory. It was sponsored by community agencies and taught by Extension Community Nutrition Educators using established ELL pedagogy.
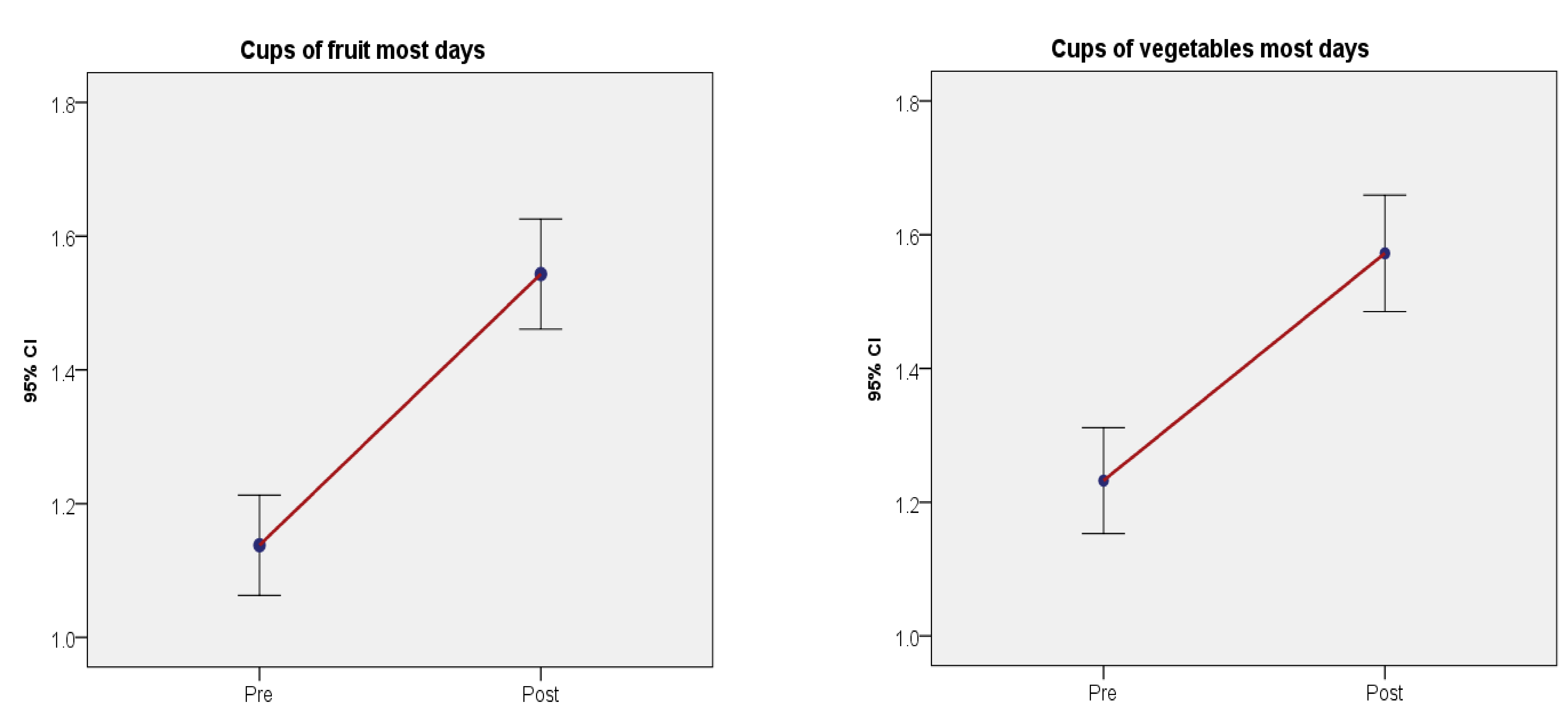

Table 1. Correlations between the number of sessions attended and the measured outcomes

1. Total Number of Sessions Attended

2. Diet Quality

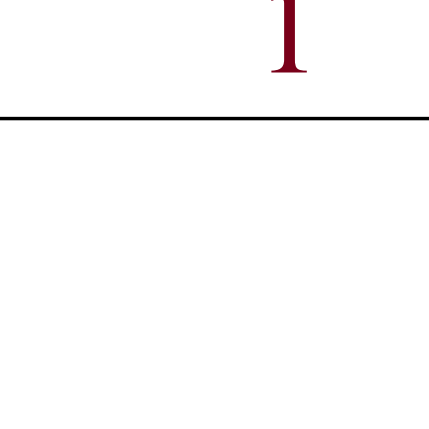

3. Resource Management $\quad .229^{* *} \quad .224^{* *}$

4. Food Safety

5. Cups of fruit

$.250 * * \quad .032$

6. Cups of Vegetable

$.082^{*} \quad .198^{* * *}$

196

${ }^{*} p<.05,{ }^{* *} p<.01$

\begin{tabular}{lllll}
$.118^{* *}$ & $.250^{* *} \quad .244^{* *} \quad .132^{*} \quad .716^{* *}$ \\
\hline
\end{tabular}

\section{CONCLUSION \& IMPLICATIONS}

Statistically significant improvements were noted in reported food intake, food safety and food resource management practices. Improvements were associated with the number of sessions attended: $r=.207, p<.001$ (food intake) $r=.250, p<.001$ (food safety practices); and $r=.229, p<.001$ (resource management practices $)(n=298-301)$

Results suggest the Simply Good Eating-ELL program promotes positive dietary changes. People attending more sessions showed higher positive changes.
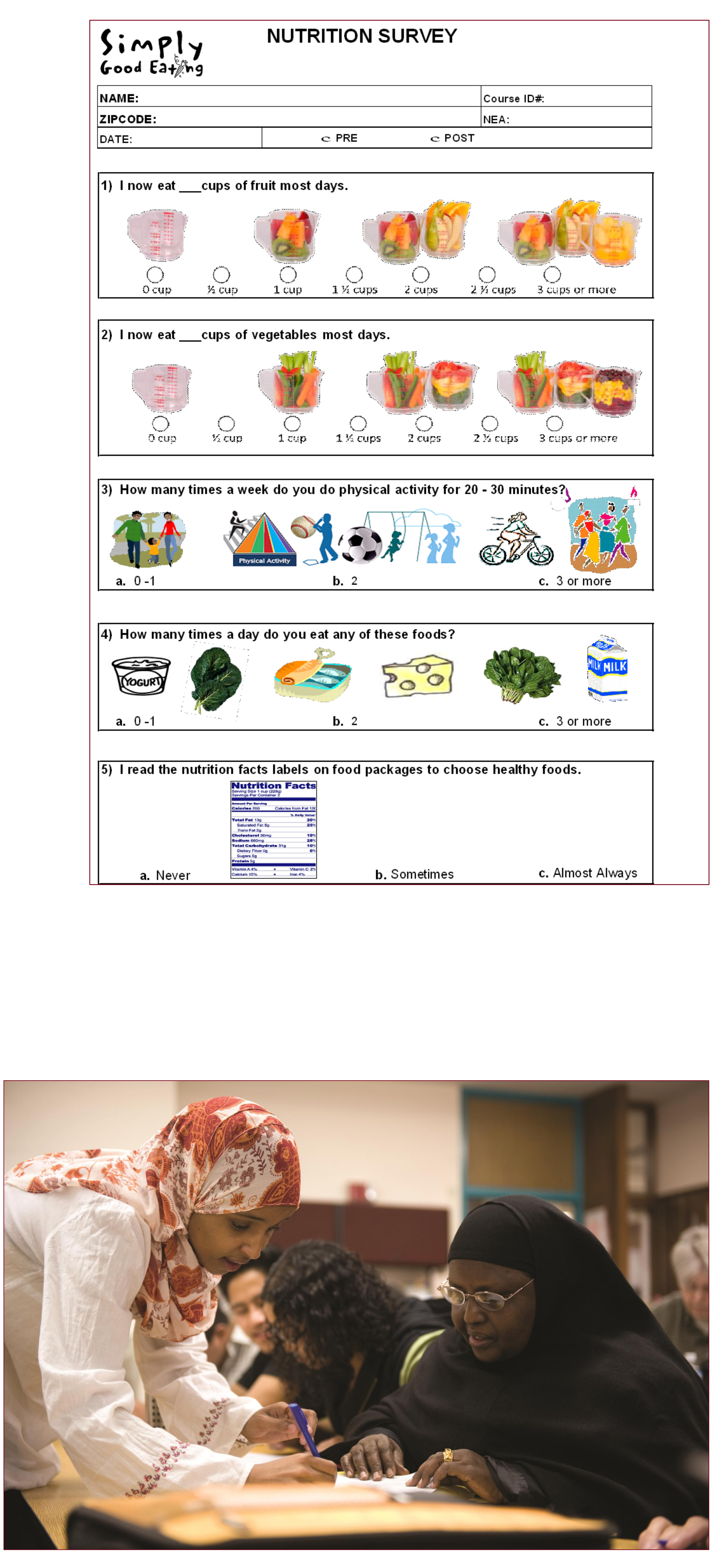